\title{
Ship Energy Saving And Emission Reduction
}

\author{
Dong Xiaoliang ${ }^{1 *}$ \\ ${ }^{1}$ School energy and power engineering, Wuhan university of technology, Wuhan, Hubei, 430063, China
}

\begin{abstract}
At present, the energy issue is a common problem faced by all industries. The use of effective energy-saving and emission reduction methods in the shipping process can save the cost of shipping. As the price of oil on ships continues to rise, energy-saving technologies for ship power stations and electrical equipment have attracted widespread attention. The use of energy-saving and emission-reduction technologies can save energy consumption, reduce environmental pollution caused by the shipping process, and obtain both economic and environmental benefits. This article briefly describes the importance of energy saving and emission reduction of ship power stations and electrical equipment on board. It explains the application of specific energy saving and emission reduction methods from the aspects of ballast water system modification, installation of desulfurization system and application of frequency conversion energy saving technology.
\end{abstract}

\section{INTRODUCTION}

With the deteriorating international environment, international maritime affairs has higher requirements for the discharge costs of ship diesel engines based on the current actual situation. Therefore, in practice, it is necessary to meet the requirements of energy conservation and emission reduction, and actively develop new technologies to effectively control the generation of pollutants, ensure that the quality of waste generated by ships during navigation meets the standard, and have a positive impact on environmental improvement. Ship diesel engines generate a large amount of waste during the process of starting. This is the process that fuel must pass through. It contains water vapor, carbon dioxide and oxygen, and also some gases that are harmful to the atmosphere, such as carbon monoxide, hydrocarbons and sulfur Oxygen compounds and so on. The main factor leading to the presence of these pollutants is the insufficient combustion during internal combustion, which harms the environment.

\subsection{What the marine environment means for humans}

As we all know, on the irregular sphere of the earth, the area of the ocean occupies $71 \%$ of the total area. According to modern scientific research, the earliest life on earth originated in the ocean, and the ocean is the cradle of human life; the ocean is rich in water. Resources bear the global water cycle system, and can even affect global temperature changes. The ocean contains a large number of rich biological resources, which provides a basis for the research of biologists. The rich resources in the ocean provide humans with food and medicine. And mineral resources, etc.; the tidal change of the ocean itself is rich in a large amount of energy for power generation; the transportation efficiency of the ocean is the highest, and coastal cities and ports near the ocean can basically develop the economy rapidly. But today, the ocean is the ultimate source of global pollution. However, while the ocean is nurturing humans, humans are also rapidly destroying the oceans. Therefore, due to the destructive destruction of the marine environment by humans, which has caused climate change, rising sea levels will cause a large number of coastal cities to be submerged and cause humans The life hazard and economic loss will be unpredictable. Therefore, strengthening the energysaving and emission-reduction work of ships has become the top priority of the development of shipping industry in various countries around the world.

\subsection{Problems Facing Energy Saving and Emission Reduction in Navigation}

Among all the transportation routes, maritime transportation is relatively environmentally friendly and low energy consumption compared to other types of transportation methods. This has led to the continuous development of the maritime transportation industry, and carbon emissions have been ignored. Through the development process in recent years, relevant personnel have carried out a professional analysis of the carbon emissions of the shipping industry, and found that on the road of maritime transportation, it is necessary to pay attention to the application of ship energy-saving and emission reduction technologies. As far as the current development of the world economy is concerned, the transportation industry is one of the industries with high energy consumption, and maritime transportation is one

* Corresponding author: 1362100895@qq.com 
of the main modes of the transportation industry, and its proportion is also large. The rate of increase in carbon emissions is increasing with each passing day.

\section{Energy saving and emission reduction methods}

\subsection{Optimize the diesel combustion process}

\subsubsection{Improving high-pressure boosting technology}

The high-pressure boosting technology can significantly increase the overall pressure of the diesel engine, thereby reducing the energy consumption under normal conditions of use. At this stage, the popular supercharged products on the market have been able to reach a high pressure ratio of 5.2, and are even continuously optimizing to the extent of ultra high pressure ratio. However, the high-pressure boosting technology does not just stop at increasing the high-pressure ratio. It can be said that increasing the pressure ratio does not play a prominent role in improving the function and performance of the diesel engine. Therefore, it is also necessary to continuously improve the supercharging system and supercharging technology, such as equipping with exhaust bypass and increasing variable cross section.

\subsubsection{Optimization of electronically controlled high- pressure common rail fuel injection technology}

The power-controlled high-pressure common rail fuel injection combustion technology controls the fuel in the high-pressure oil pipe through electric connection control, and then accumulates the fuel through the common rail pipe. Finally, the fuel is injected using a high-speed injection electromagnetic system or piezoelectric crystal Combustion and injection process. The effective use of high-pressure common rail injection technology is beneficial to reduce the impact of injection pressure on the pulsating fuel supply characteristics of positive displacement reciprocating pumps, further improving the independence of both the fuel supply and the injected fuel. It can optimize the fuel combustion process, and then reduce the generation of harmful substances. At present, with the continuous development of China's common rail pipelines and the continuous improvement of common rail technology, the common rail system has been significantly improved, and the addition of pressure accumulators has laid a material foundation for the pressure storage function.

\subsubsection{New gas combustion technology}

In the process of gas combustion, the combustion temperature has reached the specified range, but the gas still appears uneven and uneven. In theory, a gas explosion is likely to occur. However, if the fuel is not burned sufficiently, it will lead to the release of harmful gases and increase air pollution. Aiming at the phenomenon of insufficient and uneven fuel combustion, the pre-combustion method of homogeneous materials is generally used at the present stage to burn fuels of similar quality and density equally, thereby improving the fuel combustion efficiency and reducing the content of nitrogen oxides in the combustion residue. The flame surface generated by the homogeneous gas during the mixed combustion cannot be identified, so it is impossible for the local temperature to be too high. The mixed gas can be fully fused during the combustion process, so that the combustion residues will not be Has a higher content of nitrogen oxides. After that, multipoint high-pressure injection of fuel oil such as gasoline is required to achieve the purpose of full contact between fuel and air. In fact, the working principle of diesel engines is to use compression technology for mixed combustion, so the control compression device and reference coefficient need to be reflected in the design. Design the optimal ignition point systematically. However, it must be confirmed that the working cylinder is fully mixed before the ignition.

\section{Energy saving and emission reduction method for ship power station and on-board electrical equipment}

\subsection{Retrofit ballast water system}

In the application of ballast water system, it mainly includes three processes: filtration, electrolysis and neutralization. The filtering process is a ballast process. Filters are mainly used to filter ballast water. At this stage, fine particles with a particle size of $>50 \mu \mathrm{m}$ and biological filtration can be filtered out. In the electrolysis process, ballast water is introduced into the electrolysis device from the main pipeline, and the plankton is killed by the solution produced by electrolysis. The analyzer and the control system are used to control the pipeline. The neutralization link uses an automatic control system to control the neutralization dose according to the comparison of the chlorine concentration in the ballast water and the IMO value.

Modification of the loading water system can improve the energy efficiency of equipment in ship power stations. During the conversion process, the three units of filtration, electrolysis, and neutralization were mainly modified. BC-5000 device is selected. The rated processing capacity of this device can reach $4000 \mathrm{~m} 3 / \mathrm{h}$ $\sim 5000 \mathrm{~m} 3 / \mathrm{h}$ and the volume of electrolytic seawater is $45 \mathrm{~m} 3 / \mathrm{h}$. The size of its electrolytic unit is $3500 \mathrm{~mm} \times$ $3600 \mathrm{~mm} \times 770 \mathrm{~mm}$. The size of the device is $4000 \mathrm{~mm} \times$ $2800 \mathrm{~mm} \times 2600 \mathrm{~mm}$. This type of ship contains a relatively small filtration device, which has a relatively small footprint, and at the same time, the water treatment capacity of the filtration device is large, which can achieve a good filtration effect. The filtration process has a small impact on the pressure head, and the flushing process does not produce water interruption. It is suitable for filtering seawater in harsh environments. In addition, 
the modified filter unit can also perform manual control of time and pressure differential. In the modification of the electrolytic unit, a small-sized and high-efficiency switching power supply can be selected. In combination with a tube-plate type electrolytic cell electrolytic device, this device has high seawater electrolysis efficiency and is durable. When the amount of water to be processed increases, the volume change in the electrolytic module is small. The electrolytic cell in this device is the core component and has the same service life as the ship. In the neutralization unit, if the TRO concentration of the ballast water discharge is less than the IMO preset value, this system can temporarily not activate the neutralization unit and discharge the water that meets the emission reduction requirements to the outside of the ship's side; when the TRO concentration is greater than the IMO preset value At this time, the neutralization unit can be started immediately at the same time, and an appropriate amount of medicine is injected into the water pipe to neutralize the TRO at the same time, thereby realizing automatic flow control.

The retrofitted device has mature and reliable fire fighting technology and can handle relatively turbid seawater. The advanced technology is used to reform the electrolytic branch circuit, and only $1 \sim 2 \%$ of the main pipeline seawater is introduced into the electrolytic tank from the ballast pipeline. There is no need to flow all the ballast water through the electrolytic tank, and no Make changes to facilitate the design of various new ships and the transformation of traditional ships. The long electrolysis unit of the device has a small size, so it has the characteristics of high electrolysis rate and low power consumption. In the design of new ships, a modular overall design method can be used to ensure the rational use of ship space. With regard to the transformation of old ships, the equipment can be divided into three to seven different modules as a whole and designed in a narrow space of the ship. At the same time, the independent functions of each module are better, which can be applied to different routes. The converted ballast water system has lower operating costs and maintenance costs, and has good energy saving and emission reduction characteristics.

\subsection{Installation of desulfurization system}

In order to reduce the environmental pollution caused by the sulphur and oxygen compounds generated during the ship's navigation, and at the same time reduce the ship's energy consumption, a desulfurization system can be installed in the ship to achieve this goal using desulfurization technology. At present, three types of technology are often used: seawater desulfurization, gypsum desulfurization, and dry desulfurization. In terms of seawater desulfurization, the $\mathrm{SO} 2$ in the flue gas is mainly relied on the natural neutralization capacity of the seawater and the acid-base buffering performance. This process needs to be completed by means of seawater supply and drainage systems, water quality recovery, flue gas systems, and $\mathrm{SO} 2$ absorption systems. Because the seawater desulfurization process is simple, the application process is energy-saving and environmentally friendly, and the pollution to the environment is small, it has become one of the main ways of ship exhaust treatment. In terms of gypsum desulfurization, limestone is mainly used to grind it into powder, add appropriate water to configure it into a lime slurry, and neutralize and oxidize it to generate gypsum. At present, this process is widely used in the flue gas desulfurization process. After adding appropriate acidic chemicals, the desulfurization efficiency can be increased by more than $90 \%$. In terms of ship tail gas treatment, the application process of the process can be optimized, a desulfurization system can be installed, the system management process can be simplified, the system can occupy less space, and the desulfurization efficiency can be increased to prevent greater corrosion and wear on the equipment. In terms of flue gas desulfurization, limestone slurry is mainly used as a preparation system, which cooperates with reaction towers, purification devices, conveying devices, and control systems. Its desulfurization efficiency can reach $70 \% \sim 95 \%$, which can achieve good results in the treatment of low sulfur fuel. Ships usually use heavy fuels, which have a high sulfur content. Therefore, it is necessary to improve the tail gas treatment process, add desulfurization devices, use desulfurization absorbents, and maximize product recovery and reuse to prevent the desulfurization process.

\subsection{Efficient use of frequency conversion technology}

For a ship to use energy efficiently, a frequency conversion system is used. The frequency conversion system is set to input three items of AC power into the power grid. After the application of circuits such as precharging, filtering, rectification, and braking chopper, it is converted into DC power and then transmitted to different sources. Of the inverter. After the control system receives the instructions from the control system on board, it controls the output frequency and voltage of the inverter to ensure the cooperative operation of the motors. The frequency converter installed in the frequency conversion system is connected to the public DC line through a fuse. This design method can isolate the front-end rectification function without changing the original frequency converter to meet the requirements of normal motor operation. The energy saving principle of this frequency conversion system is that there are two operating states in each frequency converter. 1) Electric traction. 2) Braking power generation. During the operation of the ship, the DC bus can effectively take advantage of its mutual energy feeding. Some inverters are under the condition of electric traction, and other inverters are under the condition of braking power generation. The electric energy in the converter can be fed back to the DC common bus, and the inverter can be used in the electric working condition, which solves the problem that the chopper resistance consumed by the braking link of the independent inverter system is too high. For example, during the voyage of a ship, the 
laying of the ropes is carried out with the ropes, and the energy consumed by the ropes is higher than that of the ropes. Therefore, the frequency converter needs to use the energy in the DC bus during the takeover, which is larger than the energy fed back by the frequency converter to the $\mathrm{DC}$ bus during the laying process. During the cable laying process, the energy fed back from the inverter to the bus can be fully utilized by the inverter, without the need to consider braking chopping. When the frequency conversion system is applied, the impact on the ship power station is small and the capacity of the power station is not high. When multiple frequency converters work together, they are in different power utilization states in the public bus, and the system can control the energy in it. Recycling will be carried out, which will reduce the system's consumption of a large amount of grid power and play a good energy-saving effect.

\section{Conclusion}

The energy saving and emission reduction of ships is of great significance to improving the marine environment. In fact, improving the marine environment is not only dependent on the energy saving and emission reduction of ships, but also on every aspect, every group, and everyone. Avoid throwing garbage into the sea, do not discharge unfiltered waste oil and waste gas into the sea, eat the remaining food and drink the remaining beverage sodas, etc. The best time to protect the environment is 10 years ago. Second, It is now. To protect the marine environment is to protect humanity itself. We hope that through the efforts of all human beings, we will give the sea and humanity a better tomorrow.

\section{References}

1. Zhu Jibing.Analysis of Energy Saving and Emission Reduction Technology for Ship Design, [J], Technical Analysis, 2018 (9): 72

2. $\mathrm{Xu}$ Jianhao, Gong Tuxiang. Problems and Countermeasures of Energy Saving and Emission Reduction in China's Shipping Industry [J], World Shipping, 20: 42-44.

3. Chen Baozhong, Fu Aiyi, Sun Yongming. Analysis and research on energy saving technology of ship deceleration and main engine derating output, $[\mathrm{J}]$, China Navigation, 2005 (1).

4. Yue Guoliang, Li Nan. Research and Development Trend of Diesel Engine Energy Saving and Emission Reduction Technology [J]. China Water Transport, 2009, (4): 25-28.

5. Yang Zilong.Development Trends of Energy-Saving and Emission Reduction Technology for Marine Diesel Engines [J]. Diesel Engines, 2013, (3): 21-24.

6. Liu Haiming, Zhang Tiwei, Zhang Lei. Discussion on Development of Energy Saving and Emission Reduction Technology for Marine Diesel Engine [J]. Science Technology and Enterprise, 2015 (19): 117. 